Research Article

\title{
Activated Bledug Kuwu's Clay as Adsorbent Potential for Synthetic Dye Adsorption: Kinetic and Thermodynamic Studies
}

\author{
Sri Lestari ${ }^{1}$, M. Muflihah ${ }^{1}$, Ratna Kusumawardani ${ }^{1}$, Mukhamad Nurhadi $^{1, *}$, \\ Yuniati Mangesa ${ }^{1}$, Fathur Insani Ridho', Robbiatul Adawiyah ${ }^{1}$, Pristiningtyas Ambarwati ${ }^{1}$, \\ Siti Rahma ${ }^{1}$, Sin Yuan Lai ${ }^{2,3}$, Hadi Nur ${ }^{4,5}$ \\ ${ }^{1}$ Department of Chemical Education, Universitas Mulawarman, Kampus Gunung Kelua, Samarinda, 75119, East \\ Kalimantan, Indonesia. \\ ${ }^{2}$ School of Energy and Chemical Engineering, Xiamen University Malaysia, Selangor Darul Ehsan 43900, \\ Malaysia. \\ ${ }^{3}$ College of Chemistry and Chemical Engineering, Xiamen University, Xiamen 361005, China. \\ ${ }^{4}$ Center for Sustainable Nanomaterials, Ibnu Sina Institute for Scientific and Industrial Research, Universiti \\ Teknologi Malaysia, Johor Bahru, 81310, Malaysia. \\ ${ }^{5}$ Central Laboratory of Minerals and Advanced Materials, Faculty of Mathematics and Natural Sciences, State \\ University of Malang, Indonesia.
}

Received: 10 ${ }^{\text {th }}$ October 2021; Revised: 25th October 2021; Accepted: 25 ${ }^{\text {th }}$ October 2021 Available online: 29th October 2021; Published regularly: March 2022

\section{Abstract}

Bledug Kuwu is one of the geological phenomena as a mud volcano that occurs in Kuwu, Purwodadi, Grobogan, Central Java, Indonesia. The evaluation of Bledug Kuwu's clay as one of the adsorbents for synthetic dyes has been carried out. The preparation of the adsorbent started with washing the clay with distilled water, followed by activation with a solution of hydrochloric acid $(1 \mathrm{M})$ under mechanistic stirring for overnight. The $\mathrm{C}-\mathrm{H}$ and $\mathrm{O}-\mathrm{H}$ groups found on the clay adsorbent could attract methylene blue by dispersion forces and hydrogen bonding. Hydrocloric acid activation process for clay can increase surface area from 49 to $70 \mathrm{~m}^{2} \cdot \mathrm{g}^{-1}$, meanwhile, reducing the average crystal size from 48.3 to $43.4 \mathrm{~nm}$. The dye removal capacity increased from 34 to $40 \mathrm{mg}$. ${ }^{-1}$ in corresponding to the increase of the temperature from 30 to $50{ }^{\circ} \mathrm{C}$. The results showed that the equilibrium adsorption capacity of activated Bledug Kuwu's clay reached $99 \%$ in an adsorption time of $20 \mathrm{~min}$. The kinetic models of methylene blue adsorption onto $\mathrm{BKC}$ and $\mathrm{ABKC}$ adsorbents follow the pseudo-second order and the adsorption process is spontaneous with free energy $(\Delta G)$ as $-23.519 \mathrm{~kJ} . \mathrm{mol}^{-1}$.

Copyright (C) 2021 by Authors, Published by BCREC Group. This is an open access article under the CC BY-SA License (https://creativecommons.org/licenses/by-sa/4.0).

Keywords: Clay; Methylene blue; Adsorption; Kinetic; Thermodynamic

How to Cite: S. Lestari, M. Muflihah, R. Kusumawardani, M. Nurhadi, Y. Mangesa, F.I. Ridho, R. Adawiyah, P. Ambarwati, S. Rahma, S.Y. Lai, H. Nur (2022). Activated Bledug Kuwu's Clay as Adsorbent Potential for Synthetic Dye Adsorption: Kinetic and Thermodynamic Studies. Bulletin of Chemical Reaction Engineering \& Catalysis, 17(1), 22-31 (doi:10.9767/bcrec.17.1.12473.22-31)

Permalink/DOI: https://doi.org/10.9767/bcrec.17.1.12473.22-31

\section{Introduction}

Various types of dyes are used to improve the colouring processes in textile, paper, rubber,

\footnotetext{
* Corresponding Author.

Email: nurhadi1969@yahoo.co.id (M. Nurhadi);

Telp.: +62 81346482251; Fax: +62 541743929
}

plastics, leather, cosmetic, pharmaceutical, and food industries. Some dyes contain heavy metals in their chemical structure, such as copper, cobalt and chromium. There are many types of dyes used in industries like reactive dyes, disperse dyes, acid dyes and sulphur dyes. Reactive dyes have significant adverse effect to the envi- 
ronment because they are not easily degraded by conventional biological treatments. Therefore, they are harmful if being released without any appropriate treatments. Accumulation of dyes in water bodies have negative impacts to the aquatic environment, such as: infertility of the soil, increased amount of chemical oxygen demand (COD) in water, and reduced light penetrability that can influence the photosynthetic processes of aquatic plants. It also can pose serious hazards to the health of living beings, such as: increasing of the heart rate, vomiting, shock, cyanosis, jaundice, quadriplegia and tissue necrosis in human and even carcinogenic [1-2]. Therefore, removal of dyes is an important aspect of wastewater treatment before discharge, as it is difficult to remove dyes from effluent by the conventional wastewater purification systems. Thus, the removal of dyes from environment is very critical. A number of technologies have been developed for removal and recovery of dyes including physicochemical, chemical, and biological methods, such as: coagulation and flocculation [3-5], adsorption [69], ozonation [10], electrochemical [3], fungal decolorization [11], microbiological or enzymatic decomposition [12]. Among all these technologies, adsorption is widely used for removal and recovery of dyes due to its simplicity of equipment and operation, and the possibility of using a solid adsorbent for numerous extraction cycles without losses in the dyes extraction capacity [13]. Therefore, extensive efforts have been devoted to research and characterization of new adsorbents for specific dyes with high removal capacities.

Adsorption is the main industrial separation technique for the purification of waste media. It is a mass transfer operation in which a solid material can selectively remove dissolved components from an aqueous solution by attracting dissolved solutes to its surface. Therefore, it involves the interphase accumulation of concentrated substances at a surface or at the interphase. That is rapidly gaining prominence due its proven efficiency and great potential as means of producing quality effluent [14]. Activated carbon is the most popular and widely used adsorbent for adsorption of dyes in wastewater treatment [15-18], however, it is expensive. Therefore, there is a growing interest in using low-cost, easily available materials for the adsorption of dyes. Clay has attracted much attention due to its abundant, inexpensive, environmentally friendly materials, large catalytic support, large surface area, mechanical stability, and low cost which make it a promising adsorbent [19-23].
Herein, we report simple, economical and ecofriendly strategy for capturing and removing dyes from aqueous solutions. Bledug Kuwu is a mud volcano that occurs in Kuwu, Purwodadi, Grobogan, Central Java, Indonesia. Bledug Kuwu mud eruptions are always accompanied by water with a high salt content. Clay of Bledug Kuwu that formed from a mud are abundant, barren, inexpensive. This natural clay from Bledug Kuwu is the newly found material, which is potentially used as an adsorbent to mitigate the water pollution. To date, only one published work has reported on the use of resin adsorbent as the ion-exchanger to selectively recover alkali metals $(\mathrm{Li}, \mathrm{K}$, and $\mathrm{Na}$ ) from the Bledug Kuwu brine solution [24]. Since there is limited finding on the properties of this natural clay, thus it becomes our motivation to explore and unleash its potential that could benefit to humankind. Prior to any adsorption activity, the natural clay was activated by using hydrochloric acid (1 M) to dissolve chlorine ions and to increase surface area. Raw and activated Bledug Kuwu's clay were tested to remove the methylene blue synthetic dyes from aqueous solution. In this research, the effect of contact time and initial concentration of methylene blue were used to determine the equilibrium adsorption capacity and to investigate the kinetic process in the adsorption by Lagergren and Svenska equations. The effect of temperature was used to study the thermodynamic parameter of methylene blue dye adsorption process via Van't Hoffs plots.

\section{Materials and Methods}

\subsection{Materials Preparation}

The raw clay material was collected from Bledug Kuwu Central Java, Indonesia. The raw clay was washed by distillate water and subsequently dried at $110{ }^{\circ} \mathrm{C}$ overnight. The dried powder clay was labeled as BKC. Hydrochloric acid was supplied by Merck. Methylene blue was purchased from Merck.

\subsection{Activated Clay}

The powder clay was activated by hydrochloric acid solution. Every one gram powder clay was immersed in $10 \mathrm{~mL}$ hydrochloric acid (1 M, Merck) and stirred for $24 \mathrm{~h}$ at room temperature. The sample was filtered and dried at $110{ }^{\circ} \mathrm{C}$ overnight. The activated powder clay was labeled as ABKC. 


\subsection{Samples Characterization}

The samples were characterized by using FTIR, XRD, SEM-EDX and adsorptiondesorption isotherm. The functional groups in the samples were detected by using FTIR spectrometer (IR-Prestige-21 Shimadzu). XRD instrument (Phillips PANalytical X'Pert PRO) was used to identify the crystallinity and phase content of the samples with the $\mathrm{Cu}-\mathrm{K}_{\mathrm{a}}(\lambda=$ $1.5406 \AA$ ) radiation and range of $2 \theta\left(^{\circ}\right)$ from 7 to 60. The SEM-EDX (FEI Inspect S50) instrument was used to determine the surface morphology and element containing of the samples. The nitrogen adsorption-desorption isotherms that were created from the data collected from a Quantachrome Nova version 11.0 instrument was used to calculate the surface area, porevolume, and pore size distribution of the samples.

\subsection{Adsorption Test}

Adsorption capability of samples were tested with methylene blue dye. The adsorbent $(0.0625 \mathrm{~g})$ was inserted into a test tube containing $25 \mathrm{~mL}$ of methylene blue dye (100 mg.L $\left.\mathrm{L}^{-1}\right)$. The experiment was carried out to study the effect contact time, the initial concentration of dye, and the effect of temperatures operating condition. The initial concentration of methylene blue dye was set to be $100-600 \mathrm{mg} . \mathrm{L}^{-1}$. The operating temperature was fixed at 30,40 and $50{ }^{\circ} \mathrm{C}$. All adsorption tests were conducted under a stirring rate of $300 \mathrm{rpm}$. When the reaction was completed, the solution was filtered,

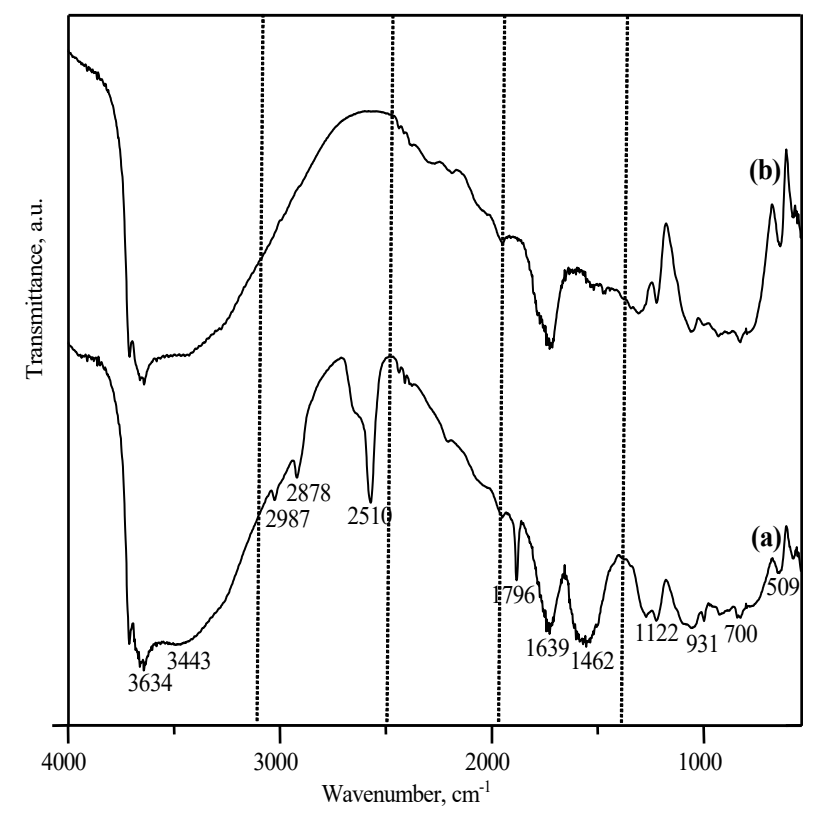

Figure 1. FTIR spectra of (a) BKC, and (b) ABKC. and the residual dye concentration was analyzed using a UV-Vis (UV VIS 100 DA-X. BONE) spectrophotometer at $660 \mathrm{~nm}$. The adsorption capacities $\left(q_{e}\right)$ is expressed as the dye adsorbed per gram of adsorbent (mg. $\left.\mathrm{g}^{-1}\right)$ and the adsorption efficiency (\%) of the adsorbent were calculated using equations below $[18,25-$ 26]:

$$
\begin{aligned}
& q_{e}=\frac{\left(C_{i}-C_{f}\right) V}{W} \\
& \text { Adsorption efficiency }(\%)=\frac{\left(C_{i}-C_{f}\right)}{C_{f}} \times 100 \%
\end{aligned}
$$

where, $C_{i}$ is the initial concentration of dye (mg. $\left.\mathrm{L}^{-1}\right), C_{f}$ is the dye concentration after adsorption time $t, V$ is the volume of dye solution $(\mathrm{mL})$ and $W$ is the adsorbent weight $(\mathrm{g})$.

\section{Results and Discussion}

\subsection{Physical Properties}

The FTIR spectra of BKC and ABKC were measured at $400-4000 \mathrm{~cm}^{-1}$ are shown in Figure 1. Both of the absorption bands around 3010-3095 $\mathrm{cm}^{-1}$ and $675-995 \mathrm{~cm}^{-1}$ indicated the functional group $\mathrm{C}-\mathrm{H}$ of alkene and aromatic ring. Absorption band around 3500-3600 $\mathrm{cm}^{-1}$ that correlated with functional group $\mathrm{O}-\mathrm{H}$ of monomer carboxylate acid and monomer alcohol (phenol). The absorption band around $2500-2700 \mathrm{~cm}^{-1}$ that correlated with the functional group $\mathrm{O}-\mathrm{H}$ of carboxylate acid with hydrogen bonding and the absorption band around $2800-2970 \mathrm{~cm}^{-1}$ that indicated as

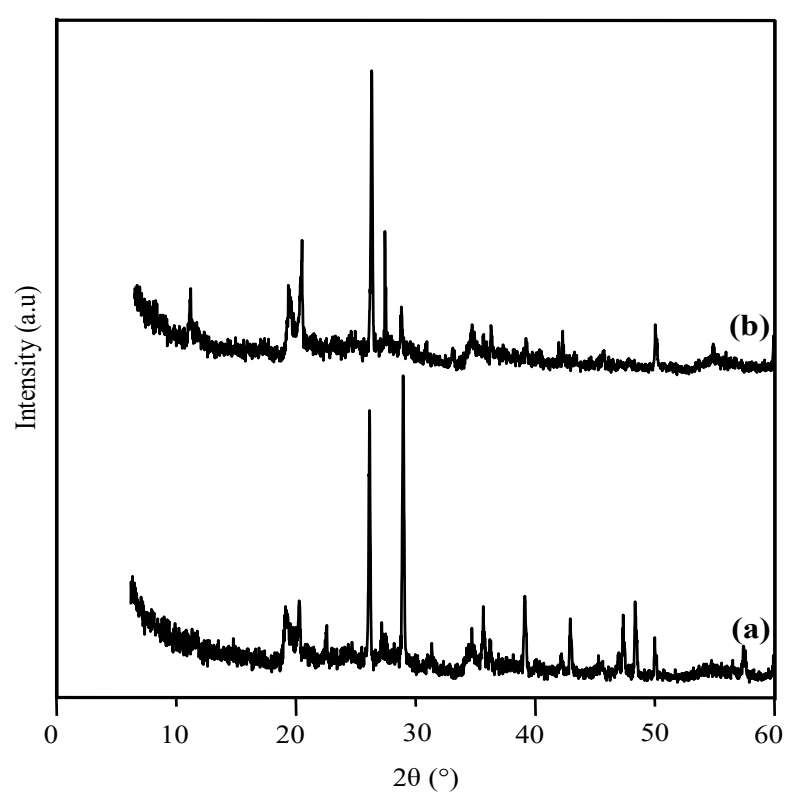

Figure 2. XRD pattern of (a) BKC, and (b) ABKC. 
functional group $\mathrm{C}-\mathrm{H}$ of alkane lose after activation process with hydrochloric acid solution. Base on the FTIR spectra, BKC adsorbent was dominated absorption band around 2512, 1798, 1425 , and $700-995 \mathrm{~cm}^{-1}$ which correlated with calcium carbonate/calcite compound [27]. After hydrochloric acid activation process the intensity absorption band of calcite decreased due to it leaching when washed with distillate water.

The XRD pattern which illustrated the crystallinity was measured at $2 \theta\left(^{\circ}\right)$ from 7 to 60 . The XRD pattern of BKC and ABKC samples are shown in Figure 2. Both samples were dominated by calcite which identified with the diffraction peaks at $2 \theta=29.3,31.7,36.0,39.4$, 43.2, 47.6, 48.6, and 57.4 ${ }^{\circ}$, which corresponded to (104), (006), (110), (113), (202), (018), (116), and (122) sets of planes. The average size of calcite in $\mathrm{BKC}$ and $\mathrm{ABKC}$ is predicted using the Debye-Scherrer equation [17,28]:

$$
D=\frac{K \lambda}{\beta \cos \theta}
$$
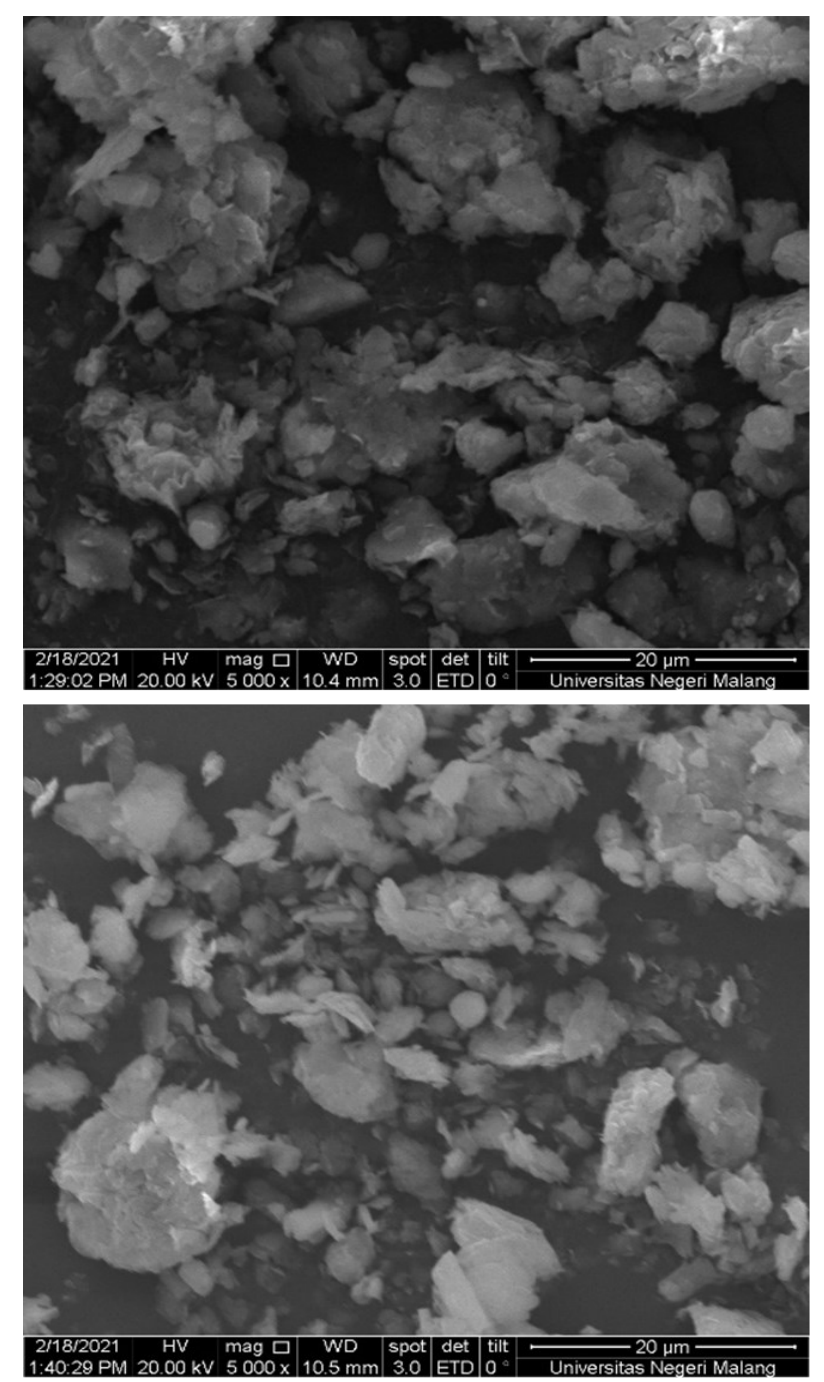

where, $D$ is the average of crystal size, $K$ is the shape factor (0.9), $\lambda$ is the X-ray wavelength $(0.15406 \mathrm{~nm}), \beta$ is the line broadening at full width at half maximum (FWHM $=0.1700$ (BKC) and $0.1890(\mathrm{ABKC})$ ) on the range $2 \theta=$ 29.33 scale in radians and $\theta$ is the Bragg angle of the peak in degrees. The average crystal size of calcite was estimated to be $48.3 \mathrm{~nm}$ (BKC) and $43.4 \mathrm{~nm}$ (ABKC). Also both samples consist the quartz which investigated by diffraction peaks at $2 \theta=26.6$. The activation process with hydrochloric acid can cause the calcite leaching which investigated by the decreasing of the peaks intensity of calcite after activation process and the particle size become small.

The SEM images of BKC and ABKC samples are exhibited in Figure 3. Both samples showed roughness surface morphology. The hydrochloric acid activation process and sequential washing with distillate water can cause the particle size become small and many elements ( $\mathrm{Na}, \mathrm{Cl}$, and $\mathrm{K}$ ) leaching from the samples. The elements in the BKC and ABKC are depicted
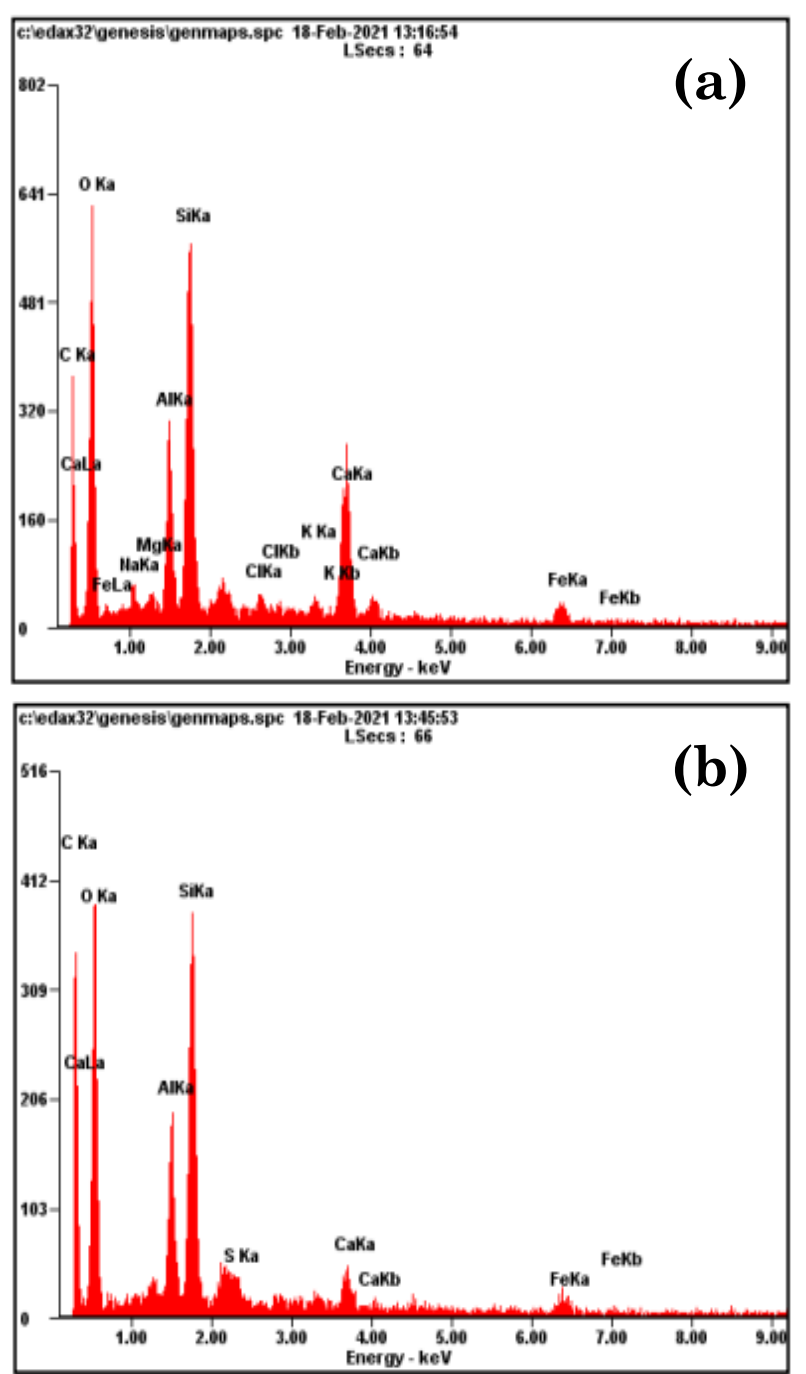

Figure 3. SEM-EDX Image of (a) BKC, and (b) ABKC. 
with SEM-EDX result in Table 1. Based on EDX results, the activation process by using $\mathrm{HCl}$ has caused leaching of several alkali metals from the Bledug Kuwu clay, including K, $\mathrm{Na}, \mathrm{Ca}$ ions. Surprisingly, the loss of $\mathrm{Cl}$ ion is also detected and this might due to its dissolution with the alkali metals in the preparation process.

Figure 4 shows nitrogen adsorptiondesorption isotherms of BKC and ABKC. All isotherms of catalysts were Type IV in the IUPAC classifications, which are a typical isotherm for mesoporous materials. The isotherms of both adsorbent exhibited clear hysteresis loops in the relative pressure range $\sim 0.453-$ 0.991 (BKC) and $\sim 0.453-0.993$ (ABKC). The $\mathrm{BET}$ surface area, pore-volume, and mean pore size of BKC and $A B K C$ were obtained from the nitrogen adsorption-desorption analysis. The complete data are listed in Table 2. The pore size distribution of BKC and $\mathrm{ABKC}$ indicated that the presence of uniform mesopores such as 2.3 and $2.5 \mathrm{~nm}$, respectively. The BET surface area and pore volume showed the following values; $48.8 \mathrm{~m}^{2} . \mathrm{g}^{-1}, 0.056 \mathrm{~cm}^{3} \cdot \mathrm{g}^{-1}$ for BKC and 69.9

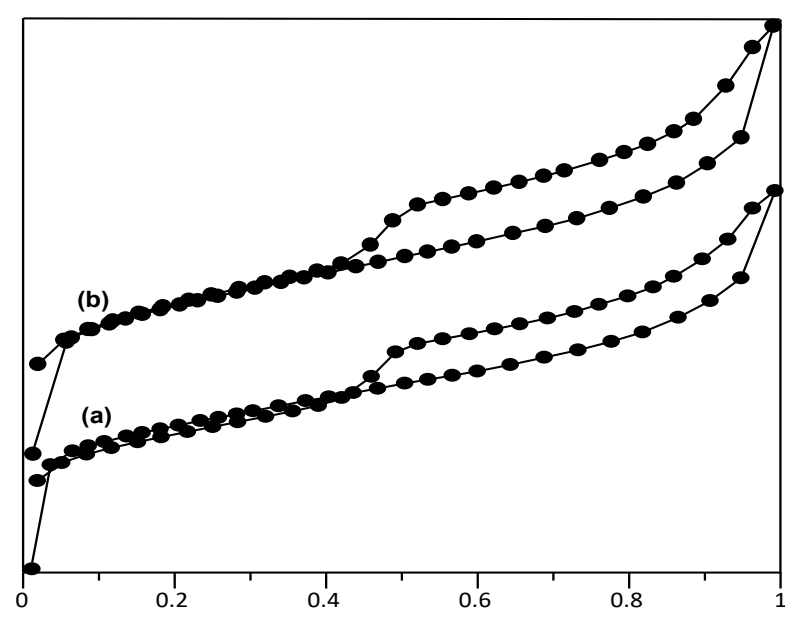

Figure 4. Isotherm BET of (a) BKC, and (b) ABKC. $\mathrm{m}^{2} \cdot \mathrm{g}^{-1}, 0.087 \mathrm{~cm}^{3} \cdot \mathrm{g}^{-1}$ for ABKC, respectively. The complete data are shown in Table 2. It can be seen that the BET surface area and pore volume drastically increased when BKC was activated with hydrochloric acid solution to be ABKC.

\subsection{Effect of Contact Time}

The effect of contact time on the adsorption of methylene blue on BKC and ABKC adsorbents is displayed in Figure 5. These results indicated that the equilibrium adsorption was reached within 5 min for BKC with dye adsorbed $\sim 98 \mathrm{mg} . \mathrm{L}^{-1}$ and within $20 \mathrm{~min}$ for ABKC with dye adsorbed $\sim 99 \mathrm{mg} . \mathrm{L}^{-1}$. Both adsorbents rapidly adsorbed methylene blue within the first 5 min of contact time with adsorption capacity of $98 \%$ for BKC and $86 \%$ for ABKC. The amount of dye removal by BKC is lower than of $\mathrm{ABKC}$, most probably caused by the surface area of ABKC larger than BKC. The small sizes of the pores of BKC might have hindered the effective adsorption of the methylene blue onto the surface of the adsorbent.

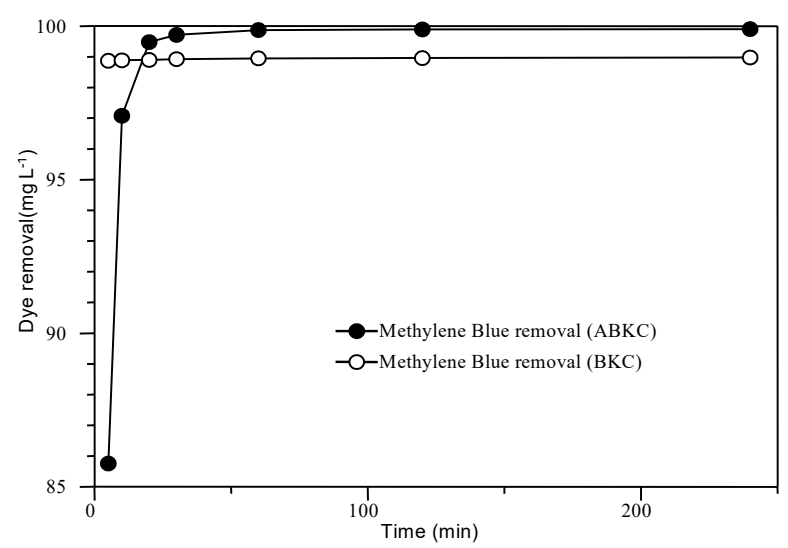

Figure 5. Effect of contact time on the amount of dye removal on $\mathrm{BKC}$ and $\mathrm{ABKC}$. Conditions: ( $\mathrm{pH}: 6.9$, concentration methylene blue 100 $\mathrm{mg} . \mathrm{L}^{-1}$, weight adsorbent $62.5 \mathrm{mg}$, at $30^{\circ} \mathrm{C}$ ).

Table 1. Elements analysis of adsorbents using SEM-EDX.

\begin{tabular}{lccccccccccc}
\hline \multirow{2}{*}{ Adsorbent } & \multicolumn{10}{c}{ Element concentration (wt\%) } \\
\cline { 2 - 10 } & $\mathrm{C}$ & $\mathrm{O}$ & $\mathrm{Na}$ & $\mathrm{Mg}$ & $\mathrm{Si}$ & $\mathrm{Al}$ & $\mathrm{Cl}$ & $\mathrm{K}$ & $\mathrm{Ca}$ & $\mathrm{Fe}$ & $\mathrm{S}$ \\
\hline Bledug Kuwu Clay (BKC) & 23.6 & 43.9 & 1.5 & 0.8 & 12.2 & 6.3 & 0.6 & 0.7 & 7.8 & 2.5 & - \\
Activated Bledug Kuwu Clay & 32.7 & 43.0 & - & 0.9 & 11.9 & 5.9 & - & - & 1.8 & 2.4 & 1.4 \\
(ABKC) & & & & & & & & & & & \\
\hline
\end{tabular}

Table 2. Physical properties of the adsorbents.

\begin{tabular}{lccc}
\hline Samples & BET surface area $\left(\mathrm{m}^{2} \cdot \mathrm{g}^{-1}\right)$ & $\begin{array}{c}\text { Pore Volume }\left(\mathrm{cm}^{3} \cdot \mathrm{g}^{-1}\right) \\
\times 10^{-2}\end{array}$ & Mean pore size (nm) \\
\hline BKC & 48.8 & 5.62 & 2.3 \\
ABKC & 69.9 & 8.72 & 2.5 \\
\hline
\end{tabular}




\subsection{Adsorption of Kinetic and Thermodynamic}

The first-order and the pseudo-second-order kinetic models were used to explain the adsorption kinetic of methylene blue adsorption onto $\mathrm{BKC}$ and $\mathrm{ABKC}$ adsorbent. Lagergren have introduced the first-order kinetic model base on the sorption capacity of adsorbent. It is expressed as [29]:

$$
\begin{aligned}
& \frac{d q_{t}}{d t}=k_{1}\left(q_{e}-q_{t}\right) \\
& \ln \left(q_{e}-q_{t}\right)=\ln q_{e, c a l}-k_{1} t
\end{aligned}
$$

where, $k_{1}$ (g/mg.h) is the rate constant for Lagergren first-order, $q_{e}$ and $q_{t}$ are the amounts of dye adsorbed per gram of adsorbent $(\mathrm{mg} / \mathrm{g})$ at equilibrium and any time $t$. The value of $k_{1}$ and $q_{e, c a l}$ can be determined from slope and intercept from plot $\ln \left(q_{e-} q_{t}\right)$ versus $t$.

The pseudo-second-order kinetic model is also based on the sorption capacity of the adsorbent. The pseudo-second-order kinetic model was introduced by Ho and McKay [30], with the equation is expressed as:

$$
\begin{aligned}
& \frac{d q_{t}}{d t}=k_{2}\left(q_{e}-q_{t}\right)^{2} \\
& \frac{t}{q_{t}}=\frac{1}{k_{2} q_{e, c a l}^{2}}+\frac{t}{q_{e, c a l}}
\end{aligned}
$$

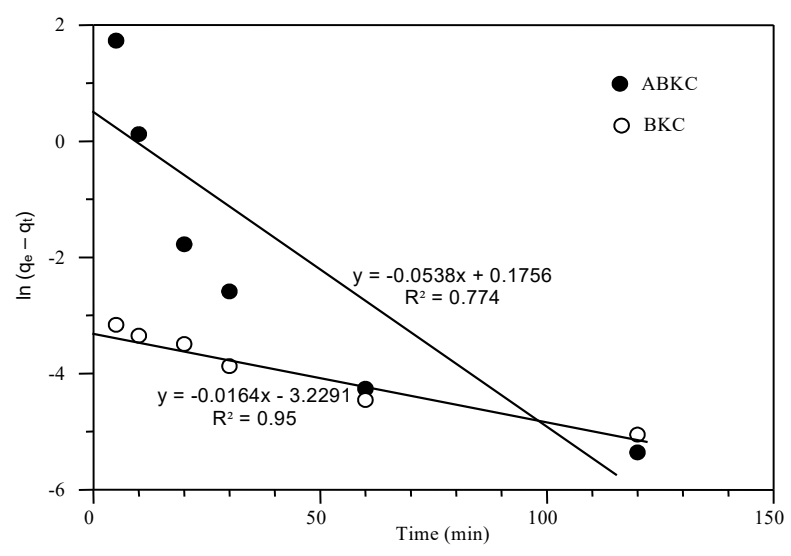

Figure 6. First order kinetic models of dye removal on BKC and ABKC. where, $k_{2}\left(\mathrm{~g} \cdot \mathrm{mg}^{-1} \cdot \mathrm{h}^{-1}\right)$ is the rate constant for pseudo-second-order, $q_{e}$ and $q_{t}$ are the amounts of dye adsorbed per gram of adsorbent (mg.g $\left.{ }^{-1}\right)$ at equilibrium and any time $t$. The value of $k_{2}$ and $q_{e, c a l}$ can be calculated from intercept and slope form the plot $t$ versus $t / q_{t}$.

The adsorption kinetic models of methylene blue adsorption onto $\mathrm{BKC}$ and $\mathrm{ABKC}$ adsorbent were investigated using pseudo-first-order and pseudo-second order kinetics models. The complete results are described in Figures 6 and 7 and also in Table 3. Based on the experiment results, the dyes removal onto $\mathrm{BKC}$ and $\mathrm{ABKC}$ adsorbent did not follow the first-order reaction model due to the correlation coefficients $R^{2}$ $<<1.000$ and the dyes removal capacity calculated $\left(q_{e, c a l}\right)<<$ the dyes removal capacity experimental $\left(q_{e, e x p}=39.589 \mathrm{mg} \cdot \mathrm{g}^{-1}\right.$ for BKC; and $39.959 \mathrm{mg} \cdot \mathrm{g}^{-1}$ for $\mathrm{ABKC}$ ).

Otherwise, the parameters kinetic models showed good compliance with the pseudosecond order. This was proven by the correlation coefficients $\left(R^{2}\right)$ for linear plots for methylene blue removal on to BKC and ABKC adsorbent were 1.000 and dyes removal capacity calculated $\left(q_{e, c a l}=39.525 \mathrm{mg} \cdot \mathrm{g}^{-1}\right.$ for BKC and $40.000 \mathrm{mg} \cdot \mathrm{g}^{-1}$ for ABKC) almost equal with the dyes removal capacity experimental $\left(q_{e, e x p}=\right.$ $39.589 \mathrm{mg} \cdot \mathrm{g}^{-1}$ for BKC; and $39.959 \mathrm{mg} . \mathrm{g}^{-1}$ for $\mathrm{ABKC})$. The experimental data for dyes removal onto on to BKC and ABKC adsorbents fit the

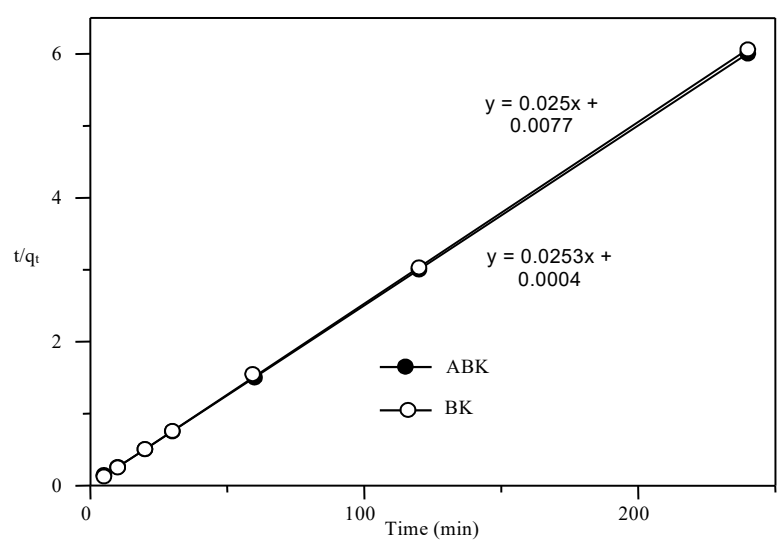

Figure 7. Pseudo second order kinetic models of

\begin{tabular}{|c|c|c|c|c|c|c|c|c|}
\hline \multirow[b]{2}{*}{ Adsorbent } & \multirow[b]{2}{*}{$\begin{array}{c}\text { Temp. } \\
\left({ }^{\circ} \mathrm{C}\right)\end{array}$} & \multicolumn{3}{|c|}{ First Order } & \multicolumn{3}{|c|}{ Pseudo Second Order } & \multirow[b]{2}{*}{$\begin{array}{c}q_{e, e x p} \\
\left(\mathrm{mg} \cdot \mathrm{g}^{-1}\right.\end{array}$} \\
\hline & & $\begin{array}{c}q_{e, c a l} \\
\left(\mathrm{mg}^{-\mathrm{g}^{-1}}\right)\end{array}$ & $\begin{array}{c}k_{1} \\
\left(\mathrm{~g} \cdot \mathrm{mg}^{-1} \cdot \mathrm{h}^{-1}\right)\end{array}$ & $\mathrm{R}^{2}$ & $\begin{array}{c}q_{e, c a l} \\
\left(\mathrm{mg} \cdot \mathrm{g}^{-1}\right)\end{array}$ & $\begin{array}{c}k_{2} \\
\left(\mathrm{~g} \cdot \mathrm{mg}^{-1} \cdot \mathrm{h}^{-1}\right)\end{array}$ & $\mathrm{R}^{2}$ & \\
\hline BKC & 30 & 0.0396 & 0.0164 & 0.950 & 39.525 & 0.0158 & 1.000 & 39.589 \\
\hline $\mathrm{ABKC}$ & 30 & 1.1920 & 0.0538 & 0.774 & 40.000 & 3.2467 & 1.000 & 39.959 \\
\hline
\end{tabular}
dye removal on $\mathrm{BKC}$ and $\mathrm{ABKC}$.

Table 3. First order and Pseudo second order kinetics for methylene blue dyes adsorption on BKC and ABKC adsorbents. 
pseudo-second order kinetic model which similar with previous research the kinetic applications for dyes removal from aqueous solution using activated carbon from Eichornia crassipes, and activated carbon from cashew nut shell [31].

The activation energy $\left(E_{a}\right)$ for adsorption process onto $\mathrm{ABKC}$ adsorbent was investigated using the Arrhenius equation. The equation is given as [32,33]:

$$
\ln k=\ln A-\frac{E_{a}}{R T}
$$

rate constant $(k)$, Arrhenius activation energy $\left(E_{a}, \mathrm{~kJ} . \mathrm{mol}^{-1}\right)$, temperature of the adsorption medium (T), the ideal gas constant (8.314 J.mol ${ }^{-1} \cdot \mathrm{K}^{-1}$ ) and the Arrhenius factor $(A)$, respectively. The Arrhenius activation energy was determined from slope of plotting $\ln k$ versus $1 / T$. The methylene blue adsorption onto $\mathrm{ABKC}$ was performed at varying temperature 30,40 and $50{ }^{\circ} \mathrm{C}$. The rate constant from every process was proposed such as $3.246 \mathrm{~mol}^{-1}$.L. $\mathrm{s}^{-1}$ (at $30{ }^{\circ} \mathrm{C}$ ); $8.333 \mathrm{~mol}^{-1} . \mathrm{L} \cdot \mathrm{s}^{-1}$ (at $40{ }^{\circ} \mathrm{C}$ ); and $11.364 \mathrm{~mol}^{-1} \cdot \mathrm{L}^{-\mathrm{s}^{-1}}$ (at $50^{\circ} \mathrm{C}$ ). The slope from the plotting $\ln k$ vs $1 / T$ was used to determine activation energy and the activation energy $\left(E_{a}\right)$ value is $51.192 \mathrm{~kJ} . \mathrm{mol}^{-1}$.

The thermodynamic parameters free energy $(\Delta G)$, enthalpy $(\Delta H)$ and entropy $(\Delta S)$ were determined at different temperature in the designed experiments. The value changes of $\Delta H$ and $\Delta S$ of adsorption were determined with the Van't Hoffs equation [33,34]:

$$
\ln K_{C}=\frac{\Delta S}{R}+\frac{\Delta H}{R T}
$$

with $K_{C}$ is the equilibrium constant which calculated by the equation:

$$
K_{C}=\frac{C_{1}}{C_{2}}
$$

where, $T, R, C_{1}$ and $C_{2}$ are temperature (K), the gas constant $\left(8.314 \mathrm{~J} . \mathrm{K}^{-1} \cdot \mathrm{mol}^{-1}\right)$, the quantity of methylene blue dye adsorbed per unit mass of adsorbent and the concentration of methylene blue dye in aqueous phase, respectively. The linier plot of $\ln K_{C}$ versus $1000 / T$ was used to determine of $\Delta S$ and $\Delta H$ which calculated from the slope and intercept. The positive value of $\Delta S$ indicates that the increase in randomness of ongoing process. The negative value of $\Delta H$ indicates that the adsorption process is exothermic in nature. Furthermore, the value of $\Delta G$ was calculated with follow the equation as [35-36]:

$$
\Delta G=\Delta H-T \Delta S
$$

The feasibility and spontaneity of adsorption process was shown by the negative value of $\Delta G$ at each temperature.

Based on Figure 8, the effect of temperature on the dye removal capacity onto ABKC adsorbent was used to investigate thermodynamic parameters. The dyes removal capacity at varying temperatures increased from 34.3 to 39.96 mg.g ${ }^{-1}$ (at $30{ }^{\circ} \mathrm{C}$ ), 38.11 to $39.96 \mathrm{mg} . \mathrm{g}^{-1}$ (at 40 ${ }^{\circ} \mathrm{C}$ ) and 38.31 to $39.93 \mathrm{mg} \cdot \mathrm{g}^{-1}$ (at $50^{\circ} \mathrm{C}$ ). It can be clearly seen that by increasing the temperature, the dye removal capacity of dye also increased slowly and reached optimum at almost $\sim 40 \mathrm{mg} . \mathrm{g}^{-1}$. The increasing of dye removal capacity when the adsorption temperature increase was as evident that the adsorption of both dyes onto ABKC adsorbent was endothermic in nature.

The Van't Hoff's plot from equation 8 was used to determine the thermodynamic parameter value of free energy $(\Delta G)$, enthalpy $(\Delta H)$ and entropy $(\Delta S)$. The $\Delta H$ and $\Delta S$ are calculated based on the slope and intercept. Furthermore, $\Delta H$ and $\Delta S$ were used to determine $\Delta G$ according to Equation (8). The complete data of thermodynamic parameter adsorption test onto

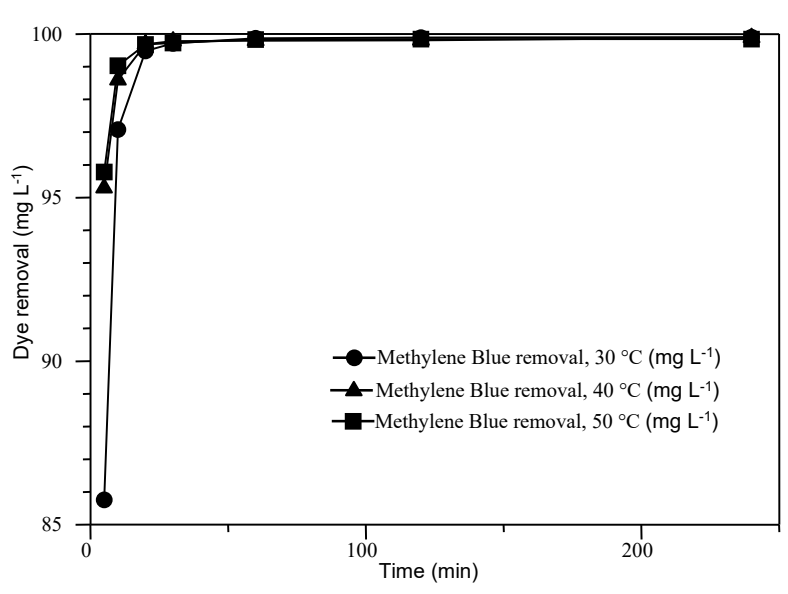

Figure 8. The effect of contact time on methylene blue removal on ABKC. Conditions: $(\mathrm{pH}$ :

\begin{tabular}{|c|c|c|c|c|c|c|}
\hline \multirow{2}{*}{ Adsorbent } & \multirow{2}{*}{$\begin{array}{c}\Delta H \\
(\mathrm{~kJ} / \mathrm{mol})\end{array}$} & \multirow{2}{*}{$\begin{array}{c}\Delta S \\
(\mathrm{~kJ} / \mathrm{mol} \mathrm{K})\end{array}$} & \multicolumn{3}{|c|}{$\Delta G(\mathrm{~kJ} / \mathrm{mol})$} & \multirow{2}{*}{$\begin{array}{c}E_{a} \\
(\mathrm{~kJ} / \mathrm{mol}\end{array}$} \\
\hline & & & $30^{\circ} \mathrm{C}$ & $40^{\circ} \mathrm{C}$ & $50^{\circ} \mathrm{C}$ & \\
\hline $\mathrm{ABKC}$ & -8.604 & 0.0477 & -23.042 & -23.519 & -23.995 & 51.193 \\
\hline
\end{tabular}
6.9, MB: $100 \mathrm{mg} . \mathrm{L}^{-1}$, weight of adsorbent: 62.5 $\mathrm{mg}$, at 30,40 and $50^{\circ} \mathrm{C}$ ).

Table 4. Thermodynamic parameters data. 
ABKC are listed in Table 4. The values of $\Delta H$, $\Delta S$ and average value of $\Delta G$ were -8.604 $\mathrm{kJ} . \mathrm{mol}^{-1}, \quad 0.048 \mathrm{~kJ} \cdot \mathrm{mol}^{-1} \cdot \mathrm{K}^{-1}$ and -23.519 $\mathrm{kJ} . \mathrm{mol}^{-1}$, respectively. Negative value of $\Delta H$ indicates that the dye adsorption process onto $\mathrm{ABKC}$ adsorbent is exothermic in nature. The increasing in degree of system irregularities was identified by the positive value of $\Delta S$. The feasibility and spontaneity of ongoing dyes adsorption process onto ABKC adsorbent was shown by the negative value of $\Delta G$.

\subsection{Effect of Initial Concentration}

The effect of initial synthetic dye concentrations on the adsorption are shown in Figure 9. The adsorption amount of methylene blue increased when the initial concentration of methylene blue increased. At equilibrium, the amount methylene blue adsorbed increased from 79.6 to 135.8 for BKC and 79.6 to 153.9 for $\mathrm{ABKC}$ when the initial concentration of methylene blue increased from 200 to 600 mg. $\mathrm{L}^{-1}$. It is hypothesized that the increasing concentration acted as an increasing driving force to overcome all mass transfer resistances of the methylene blue dye molecules between the aqueous and solid phase, leading to an increasing equilibrium sorption until saturation was achieved. A similar trend was also reported with methylene blue onto roots, stems and leaves with methylene blue concentrations of 0.80 to $8.0 \mathrm{mg} . \mathrm{L}^{-1}$ [1]. Based on the adsorption results from various methylene blue concentrations, a series of data were obtained and then processed to determine the adsorption capacity using the Langmuir isotherm equation as follows [37]:

$$
\frac{1}{q_{e}}=\frac{1}{q_{\max } \times K_{a d s}}\left(\frac{1}{C_{e}}\right)+\frac{1}{q_{\max }}
$$

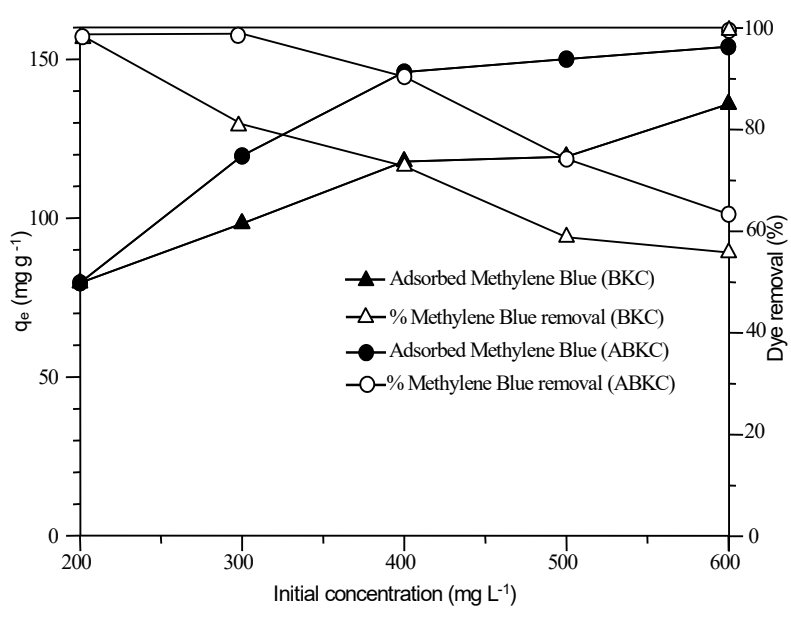

Figure 9. The effect of initial synthetic dye concentration. with graphs of $1 / q_{e}$ vs $1 / C_{e}$, then the maximum adsorption capacity $\left(q_{\max }\right)$ was calculated from the slope and intercept values, where $q_{e}$ is the number of synthetic dye adsorbed $(\mathrm{mg} / \mathrm{g}), C_{e}$ is the final concentration of methylene blue $(\mathrm{mg} / \mathrm{L})$ and $K_{a d s}$ is the Langmuir adsorption constant $(\mathrm{mg} / \mathrm{L})$. From the intercept, the maximum adsorption capacity $\left(q_{\max }\right)$ were obtained as $116.3 \mathrm{mg} \cdot \mathrm{g}^{-1}$ for BKC and $153.8 \mathrm{mg} \cdot \mathrm{g}^{-1}$ for ABKC. From slope the Langmuir adsorption constant $\left(K_{a d s}\right)$ were obtained as 2.205 for BKC and 1.625 for ABKC. The effectiveness of methylene blue adsorption was investigated by the following linear forms of Freundlich isotherm. The Freundlich isotherm is expressed as follows [13]:

$$
\ln q_{e}=\ln k_{f}+\left(\frac{1}{n}\right) \ln C_{e}
$$

where, $k_{f}$ is the roughly a measure of adsorption capacity and $n$ is the effectiveness indicator of adsorption. Figure 9 can determine $n$ and $k_{f}$ which calculated from slope and intercept of linear plot $\log C e$ vs $\log q_{e}$. The value of $n$ and $k_{f}$ were 11.7 and 77.6 for BKC and 11.2 and 98.5 for ABKC, respectively. Due to the value $n$ $>1$, it can be concluded that the adsorption of methylene blue onto BKC and ABKC adsorbent were effective.

\section{Conclusions}

The experiments of clay and activated clay from Bledug Kuwu as adsorbents have been conducted for removing of methylene blue. The clay from Bledug Kuwu was dominated by calcite and silicate. The $\mathrm{C}-\mathrm{H}$ and $\mathrm{O}-\mathrm{H}$ groups found on the clay adsorbent could attract methylene blue by dispersion forces and hydrogen bonding. Hydrocloric acid activation process for clay can increase surface area from 49 to 70 $\mathrm{m}^{2} . \mathrm{g}^{-1}$, meanwhile, reducing the average crystal size from 48.3 to $43.4 \mathrm{~nm}$. It is found that the activated Bledug Kuwu's clay (ABKC) gave the highest adsorption capacity compared to raw clay (BKC). The adsorption capacity and adsorption capacity maximum were $99 \mathrm{mg} . \mathrm{L}^{-1}$ and $153 \mathrm{mg} \cdot \mathrm{g}^{-1}(\mathrm{ABKC}) ; 98 \mathrm{mg} \cdot \mathrm{L}^{-1}$ and 116 mg.g $\mathrm{g}^{-1}$ (BKC), respectively. The kinetic models of methylene blue adsorption onto BKC and ABKC adsorbent follow the pseudo second order and the adsorption process is spontaneous with free energy $(\Delta G)$ as $-23.519 \mathrm{~kJ} . \mathrm{mol}^{-1}$. 


\section{Acknowledgements}

The authors gratefully acknowledge research funding from Fakultas Keguruan and Ilmu Pendidikan Universitas Mulawarman, East Kalimantan Province, Indonesia by contract number: 814/UN17.5/PG/2021. Sin Yuan Lai would also like to acknowledge the financial support provided by Hengyuan International Sdn. Bhd. (grant number: EENG/0003).

\section{References}

[1] Wanyonyi, W.C., Onyari, J.M., Shiundu, P.M. (2013). Adsorption of Methylene Blue Dye from Aqueous Solution Using Eichhornia crassipes. Bull, Environ. Contam. Toxicol., 91(3), 362-366. DOI: 10.1007/s00128-0131053-0

[2] Nigam, P., Armour, G., Banat, L.M., Singh, D., Marchant, R. (2000). Physical removal of textile dyes from effluents and solid-sate fermentation of dye-adsorbed agriculturalresidues. Bioresour. Technol., 72, 219-226. DOI: 10.1016/S0960-8524(99)00123-6

[3] Alinsafi, A., Khemis, M., Pons, M.N., Leclerc, J.P., Yaacoubi, A., Benhammou, A., Nejmeddine, A. (2005). Electro-coagulation of reactive textile dyes and textile wastewater. Chem. Eng. $\quad$ Process., 44, 461-470. DOI: 10.1016/j.cep.2004.06.010

[4] Alkan, M., Celikcapa, S., Demirbas, O., Dogan, M. (2005). Removal of reactive blue 221 and acid blue 62 anionic dyes from aqueous solution by sepiolite. Dyes and Pigments, $65, \quad 251-259 . \quad$ D O I : 10.1016/j.dyepig.2004.07.018

[5] Karaoglu, M.H., Dogan, M., Alkan, M. (2010). Removal of Reactive Blue 221 by Kaolinite from Aqueous Solution. Ind. Eng. Chem. Res., 49, 1534-1540. DOI: 10.1021/ie9017258

[6] Widiyowati, I., Nurhadi, M., Hatami, M., Yuan, L. (2020). Effective $\mathrm{TiO}_{2}$-Sulfonated Carbon-derived from Eichhornia crassipes in The Removal of Methylene Blue and Congo Red Dyes from Aqueous Solution. Bull. Chem. React. Eng. Catal., 15(2), 476-489. DOI: 10.9767/bcrec.15.2.6997.476-489

[7] Pelekani, C., Snoeyink, V.L. (2000). Competitive adsorption between antrazine and methylene blue on activated carbon: the importance of pore size distribution. Carbon, 38, 1423-1436. DOI: $10.1016 / \mathrm{S} 0008$. 6223(99)00261-4

[8] Pavan, F.A., Mazzocato, A.C., Gushikem, Y. (2008). Removal of methylene blue dye from aqueous solution by adsorption using yellow passion fruit peel as adsorbent. Bioresour. Technol., 99, 3162-3165. DOI: 10.1016/j.biortech.2007.05.067
[9] Sun, Q., Yang, L. (2003). The adsorption of basic dyes from aqueous solution on modified peat-resin particle. Water Research, 37, 15351544. DOI: 10.1016/S0043-1354(02)00520-1.

[10] Muthukumar, M., Selvakumar, N. (2004). Studies on the effect of inorganic salts on decolouration of acid dye effluent by ozonation. Dyes and Pigments, 62, 221-228. DOI: 10.1016/j.dyepig.2003.11.002

[11] Sikaily, A.E., Khaled, A., Nemr, A.E., Abdelwahab, O. (2006). Removal of Methylene Blue from aqueous solution by marine green alga Ulva lactuca. Chem. Ecol., 22, 149-157. DOI: 10.1080/02757540600579607

[12] Park, C., Lee, M., Lee, B., Kim, S.W., Chase, H.A., Lee, J., Kim, S. (2007). Biodegradation and biosorption for decolorization of synthetic dyes by Funalia trogii. Biochem. Eng. J., 36, 59-65. DOI: 10.1016/j.bej.2006.06.007

[13] El-Safty, S.A., Khairy, M., Shenashen, M.A., Elshehy, E., Warkocki, W., Sakai, M. (2015). Optical mesoscopic membrane sensor layouts for water-free and blood-free toxicants. Nano Research, 8, 3150-3163. DOI: 10.1007/s12274-015-0815-x

[14] Wanyonyi, W.C., Onyari, J.M., Shiundu, P.M. (2014). Adsorption of Congo Red Dye from Aqueous Solution Using Roots of Eichhornia Crassipes: Kinetic and Equilibrium Studies Energy. Procedia, 50, 862-869. DOI: 10.1016/j.egypro.2014.06.105

[15] Zhang, G., Lei, B., Chen, S., Xie, H., Zhou, G. (2021). Activated carbon adsorbents with micro-mesoporous structure derived from waste biomass by stepwise activation for toluene removal from air. J. Environ. Chem. Eng., 9(4), 105387. DOI: $10.1016 /$ j.jece.2021.105387

[16] Díez, E., Gómez, J.M., Rodríguez, A., Bernabé, I., Galán, J. (2021). Recovery of Gallium from Aqueous Solution through Preconcentration by Adsorption/Desorption on Disordered Mesoporous Carbon. J. Sustain. Metall., 7, 227-242. DOI: 10.1007/s40831-021-00336-4

[17] Kusumawardani, R., Nurhadi, M., Wirhanuddin, W., Gunawan, R., Nur, H. (2019). Carbon-containing Hydroxyapatite Obtained from Fish Bone as Low-cost Mesoporous Material for Methylene Blue Adsorption. Bull. Chem. React. Eng. Catal., 14(3), 660-671. DOI: $10.9767 /$ bcrec. 14.3.5365.660-671

[18] Giri, A.K., Patel, R., Mandal, S. (2012). Removal of $\mathrm{Cr}(\mathrm{VI})$ from aqueous solution by Eichhornia crassipes root biomass-derived activated carbon. Chem. Eng. J., 185-186, 7181. DOI: 10.1016/j.cej.2012.01.025

[19] Qhubu, M.C., Mgidlana, L.G., Madikizela, L.M., Pakade, V.E. (2021). Preparation, characterization and application of activated clay biochar composite for removal of $\mathrm{Cr}(\mathrm{VI})$ in 
water: Isotherms, kinetics and thermodynamics. Mater. Chem. Phys., 260, 124165. DOI: 10.1016/j.matchemphys.2020.124165

[20] Malima, N.M., Owonubi, S.J., Lugwisha, E.H., Mwakaboko, A.S. (2021). Development of cost-effective and eco-friendly adsorbent by direct physical activation of Tanzanian Malangali kaolinite for efficient removal of heavy metals. Mater. Today: Proceedings, 38, 11261132. DOI: 10.1016/j.matpr.2020.06.469

[21] Liu, W., Yuan, K., Yin, K., Zuo, S., Yao, C. (2021). Clay-activated carbon adsorbent obtained by activation of spent bleaching earth and its application for removing $\mathrm{Pb}$ (II) ion. Environ. Sci. Pollut. Res., 28, 711-723. DOI: 10.1007/s11356-020-10473-0

[22] Marrakchi, F., Hameed, B.H., Hummadi, E.H. (2020). Mesoporous biohybrid epichlorohydrin crosslinked chitosan/carbon-clay adsorbent for effective cationic and anionic dyes adsorption. Int. J. Biol. Macromol., 163, 10791086. DOI: 10.1016/j.ijbiomac.2020.07.032

[23] Hajjaji, W., Pullar, R.C., Labrincha, J.A., Rocha, F. (2016). Aqueous Acid Orange 7 dye removal by clay and red mud mixes. Appl. Clay Sci., $\quad 126, \quad 197-206$. D O I : 10.1016/j.clay.2016.03.016

[24] Rohmah, M., Lalasari, L.H., Natasha, N.C., Sulistiyono, E., Firdiyono, F., Soedarsono, J.W. (2020). Adsorption Behavior of Alkali Metal $\left(\mathrm{Na}^{+}, \mathrm{Li}^{+}\right.$, and $\left.\mathrm{K}^{+}\right)$from Bledug Kuwu brine by Resin Adsorbent for Purification: $\mathrm{pH}$ and Flow Rate Parameter. Orient. J. Chem., 36(2), 273-279. DOI: 10.13005/ojc/360209

[25] Wang, L. (2012). Application of activated carbon derived from 'waste' bamboo culms forthe adsorption of azo disperse dye: Kinetic, equilibrium and thermodynamic studies. J. Environ. Manag., 102, 79-87. DOI: 10.1016/j.jenvman.2012.02.019.

[26] Lim, H.K., Teng, T.T., Ibrahim, M.H., Ahmad, A., Chee, H.T., (2012). Adsorption and Removal of Zinc(II) from Aqueous Solution Using Powdered Fish Bones. APCBEE Procedia, 1, 96-102. DOI: 10.1016/j.apcbee.2012.03.017

[27] Reig, F.B., Adelantado, J.V.G., Moreno, M.C.M.M. (2002). FTIR quantitative analysis of calcium carbonate (calcite) and silica (quartz) mixtures using the constant ratio method. Application to geological samples. Talanta, 58, 811-821. DOI: 10.1016/S00399140(02)00372-7

[28] Arif, Z., Sethy, N.K., Kumari, L., Mishra, P.K., Verma, B. (2019). Green synthesis of $\mathrm{TiO} 2$ nanoparticles using Cajanus cajan extract and their use in controlling the fouling of ultrafiltration PVDF membranes. Korean J. Chem. Eng., 36(7), 1148-1156. DOI: 10.1007/s11814-019-0297-8
[29] Aksu, Z. (2005). Application of biosorption for the removal of organic pollutants: a review. Process Biochem., 40, 997-1026. DOI: 10.1016/j.procbio.2004.04.008

[30] Ho, Y.S., McKay, G. (1998). Sorption of dye from aqueous solution by peat. Chem. Eng. J., $70, \quad 115-124$. DOI: 10.1016/S00329592(98)00112-5

[31] Kumar, P.S., Ramalingam, S., Sathishkumar, K. (2011). Removal of methylene blue dye from aqueous solution by activated carbon prepared from cashew nut shell as a new lowcost adsorbent. Korean J. Chem. Eng., 28(1), 149-155. DOI: 10.1007/s11814-010-0342-0

[32] Pathania, D., Sharma, A., Siddiqi, Z.M. (2016). Removal of congo red dye from aqueous system using Phoenix dactylifera seeds. J. Mol. Liq., 219, 359-367. DOI: 10.1016/j.molliq.2016.03.020

[33] Yang, L., Zhang, Y., Liu, X., Jiang, X., Zhang, Z., Zhang, T., Zhang, L., (2014). The Investigation of Synergistic and competitive interaction between dye Congo red and Methyl blue on magnetic $\mathrm{MnFe}_{2} \mathrm{O}_{4}$. Chem. Eng. J., 246, 88-96. DOI: 10.1016/j.cej.2014.02.044

[34] Gao, J.-j., Qin, Y.-b., Zhou, T., Cao, D.-d., Xu, P., Hochstetter, D., Wang, Y-f. (2013). Adsorption of methylene blue onto activated carbon produced from tea (Camellia sinensis L.) seed shells: kinetics, equilibrium, and thermodynamics studies. J. Zhejiang University: Sci. B (Biomedic. Biotechnol.), 14(7), 650-658. DOI: 10.1631/jzus.B12a0225

[35] Chang, Y., Lai, J.-Y., Lee, D.-J. (2016). Thermodynamic parameters for adsorption equilibrium of heavy metals and dyes from wastewaters: Research updated. Bioresour. Technol., 222, 513-516. DOI: 10.1016/j.biortech.2016.09.125

[36] Du, X., Cheng, Y., Liu, Z., Yin, H., Wu, T., Huo, L., Shu, C., (2021). $\mathrm{CO}_{2}$ and $\mathrm{CH}_{4}$ adsorption on different rank coals: A thermodynamics study of surface potential, Gibbs free energy change and entropy loss. Fuel, 283, 118886. DOI: 10.1016/j.fuel.2020.118886

[37] Rahman, A., Kishimoto, N., Urabe, T. (2015). Adsorption characteristics of clay adsorbents - sepiolite, kaolin and synthetic talc - for removal of Reactive Yellow 138:1. Water and Environ. J., 29, 375-382. DOI: 10.1111/wej.12131 